\title{
Comparison of energy metabolism and nutritional status of hospitalized patients with Crohn's disease and those with ulcerative colitis
}

\author{
Azusa Takaoka, ${ }^{1,3}$ Masaya Sasaki, ${ }^{1, *}$ Mika Kurihara, ${ }^{1}$ Hiromi Iwakawa, ${ }^{1}$ Mai Inoue, ${ }^{1}$ Shigeki Bamba, ${ }^{2}$ \\ Hiromitsu Ban, ${ }^{2}$ Akira Andoh ${ }^{2}$ and Yoshiko Miyazaki ${ }^{3}$ \\ ${ }^{1}$ Division of Clinical Nutrition and 2Department of Medicine, Shiga University of Medical Science, Seta-Tsukinowa, Otsu, Shiga 520-2192, Japan \\ ${ }^{3}$ Kyoto Women's University, Graduate School of Home Economics, 35 Kitahiyoshi-cho, Imakumano, Higashiyama-ku, Kyoto 605-8501, Japan
}

\begin{abstract}
This study aimed to compare the nutritional status and energy expenditure of hospitalized patients with Crohn's disease (CD) and those with ulcerative colitis (UC). Twenty-two hospitalized patients with CD and 18 patients with UC were enrolled in this study. We analyzed nutritional status upon admission by using nutritional screening tools including subjective global assessment, malnutrition universal screening tool, and laboratory tests. We measured resting energy expenditure (mREE) of the patients with indirect calorimetry and predicted resting energy expenditure (pREE) was calculated by using the Harris-Benedict equation. Results presented here indicate no significant difference in nutritional parameters and energy metabolism between $C D$ and UC patients. In UC patients, a significant correlation was observed between $\mathrm{mREE} /$ body weight and disease activity detected by the Lichtiger and Seo indices. However, there was no correlation between mREE/body weight and Crohn's disease activity index in CD patients. Inflammatory cytokine interleukin- 6 levels correlated with $\mathrm{mREE} / \mathrm{pREE}$ in CD and UC patients while tumor necrosis factor- $\alpha$ was not. In conclusion, energy expenditure significantly correlated with disease activity in UC patients but not in CD patients. These results indicate that establishing daily energy requirements based on disease activity of UC is imperative for improving the nutritional status of patients.
\end{abstract}

Key Words: Crohn's disease, ulcerative colitis, indirect calorimetry, energy metabolism, nutritional status

I nflammatory bowel disease (IBD) such as Crohn's disease (CD) and ulcerative colitis (UC) are chronic inflammatory disorders of the digestive tract with unknown etiology. Genetic and environmental factors have been correlated with the pathogenesis of IBD, ${ }^{(1-3)}$ but the precise mechanisms remain unclear. Clinical symptoms in patients with CD include diarrhea, abdominal pain, weight loss, and other abdominal symptoms due to bowel obstruction. UC is associated with symptoms including bloody diarrhea, abdominal pain, weight loss, and fever. Furthermore, inflammation of the digestive tract and the aforementioned abdominal symptoms often lead to malnutrition. Patients with IBD have various nutritional and metabolic disturbances. Emaciation is found in $20-70 \%$ of hospitalized CD patients, ${ }^{(4,5)}$ and approximately $75 \%$ of hospitalized CD patients are undernourished, ${ }^{(6,7)}$ indicating that nutritional support is essential for CD patients. Nutritional therapies such as enteral nutrition (EN), total parenteral nutrition (TPN), and anti-tumor necrosis factor (TNF)- $\alpha$ treatment are useful induction therapies for CD patients. Although TPN is useful for bowel rest in the active stage of UC, EN does not induce or maintain remission in UC. Therefore, corticosteroids and immunosuppressive drugs are efficacious treatment options for UC patients.

It is generally accepted that the prevalence of nutritional deficiencies and malnutrition are higher in patients with $\mathrm{CD}$ than in patients with UC. ${ }^{(8)}$ Han et al. ${ }^{(9)}$ reported that the prevalence of weight loss, hypoalbuminemia, and intestinal protein loss was higher in patients with CD than in patients with UC. However, there are few reports about comparison of nutritional status between $\mathrm{CD}$ and UC patients except for this report. Protein energy malnutrition detected as body weight loss and hypoalbuminemia are observed in both CD and in UC patients.

Several studies have investigated the role of energy metabolism in patients with IBD. For example, there are reports that energy metabolism shifts to a hyper-metabolic state in CD patients. ${ }^{(10-14)}$ However, Schneeweiss et $a .^{(15)}$ indicated that measured resting energy expenditure (mREE) was not significantly different between $\mathrm{CD}$ patients and healthy controls. There are a few reports that have analyzed energy metabolism in patients with $\mathrm{UC},{ }^{(16,17)}$ and there have not been studies identifying the relationship between nutritional status and energy metabolism in IBD patients. Recently, we used indirect calorimetry to identify that mREEs of Japanese IBD patients were significantly higher than that of healthy controls. $^{(18,19)}$ Here, we are the first to describe a comparative analysis of the nutritional status and energy metabolism of hospitalized patients with CD and UC.

\section{Subjects and Methods}

Patients. Twenty-two patients with CD and 18 patients with UC were enrolled in this study. The patients were admitted to the Gastroenterology Unit of the Shiga University of Medical Science Hospital between June 2011 and March 2014. The ethics committee of the Shiga University of Medical Science approved this study. All diagnoses of CD and UC were established by using radiological, endoscopic, histological, and clinical criteria. ${ }^{(20,21)}$

Methods. The following values were measured upon admission: 1) Anthropometrics: height $(\mathrm{cm})$, weight $(\mathrm{kg})$, body mass index (BMI) $\left(\mathrm{kg} / \mathrm{m}^{2}\right)$. 2) Nutritional screening: subjective global assessment (SGA), ${ }^{(22,23)}$ malnutrition universal screening tool (MUST) ${ }^{(24)}$ nutritional risk screening 2002 (NRS2002), ${ }^{(25)}$ prognostic nutritional index $(\mathrm{PNI})(10 \times$ albumin $(\mathrm{g} / \mathrm{dl})+0.005 \times$ total lymphocyte count per cubic $\mathrm{mm}),{ }^{(26)}$ and controlling nutritional status (CONUT). $\left.{ }^{(27)} 3\right)$ Laboratory tests: levels of total protein $(\mathrm{g} / \mathrm{dl})$, albumin $(\mathrm{g} / \mathrm{dl})$, total cholesterol $(\mathrm{mg} / \mathrm{dl})$, triglyceride

whom correspondences should be addressed. E-mail: sasaki@belle.shiga-med.ac.jp 
$(\mathrm{mg} / \mathrm{dl})$, hemoglobin $(\mathrm{g} / \mathrm{dl})$, C-reactive protein $(\mathrm{CRP})(\mathrm{mg} / \mathrm{dl}) .4)$ Activity index: Crohn's Disease Activity index (CDAI) for CD ${ }^{(28,29)}$ Lichtiger index and Seo index for UC. $\left.{ }^{(30,31)} 5\right)$ Energy metabolism measured by indirect calorimetry: $\mathrm{mREE}(\mathrm{kcal} / \mathrm{kg} / \mathrm{day})$, respiratory quotients (RQ). 6) Inflammatory cytokines: TNF- $\alpha$ (pg/dl) and interleukin-6 (IL-6) (pg/dl) were determined by using commercially available ELISA kits (R\&D Systems, Minneapolis, MN).

Indirect calorimetry. mREEs and RQ were measured by using computed open-circuit indirect calorimetry (AE-300S; Minato Medical Science Co., Osaka, Japan)..$^{(18,19,32-34)}$ Indirect calorimetry was performed in the same ward in the hospital after an $8 \mathrm{~h}$ fast. Infusion of parenteral nutrition (PN) was continuous and period flow and gas calibration were performed prior to the measurements. After resting for a minimum of $30 \mathrm{~min}$, the patients were assessed in a supine position with a facemask by using a pump that drew ambient air through the facemask at a constant rate. After equilibrium was reached for $10 \mathrm{~min}$, respiratory exchange was performed continuously over a $30 \mathrm{~min}$ period. The mREE and RQ data were obtained every minute. The mREE was calculated from oxygen consumption $\left(\mathrm{V}_{2}\right)$ and carbon dioxide production $\left(\dot{\mathrm{VCO}}_{2}\right)$ by using the following Weir equation: mREE $=\left(3.94 \times \dot{\mathrm{V}} \mathrm{O}_{2}+1.11 \times \mathrm{VCO}_{2}\right) \times 1.44$. Measurement of RQ was calculated as $\mathrm{RQ}=\dot{\mathrm{V} C O}{ }_{2} / \dot{\mathrm{VO}}_{2}$. The mREE was then compared with the predicted resting energy expenditure (pREE) by using the Harris-Benedict equation for men $\{\mathrm{pREE}=66.47+$ $13.75 \times \mathrm{W}$ [weight $(\mathrm{kg})]+5.0 \times \mathrm{H}$ [height $(\mathrm{cm})]-6.75 \times \mathrm{A}$ [age (years) $]\}$ and women $\{\mathrm{pREE}=665.09+9.56 \times \mathrm{W}$ [weight $(\mathrm{kg})]+$ $1.84 \times \mathrm{H}$ [height $(\mathrm{cm})]-4.67 \times \mathrm{A}$ [age (years)]\} .

Statistical analyses. Statistical analyses were performed by using the Chi-square test when appropriate. Student's paired $t$ tests were used for the statistical analysis of parametric data, and the Mann-Whitney $U$ test was used for the statistical analysis of nonparametric data. Correlation was investigated by using Spearman rank correlation tests. Results are presented as mean $\pm \mathrm{SD}$, and a $p$ value $<0.05$ was considered statistically significant.

\section{Results}

Patient characteristics. Patient's characteristics are shown in Table 1. We excluded one subject (UC patient with BMI $28.8 \mathrm{~kg} / \mathrm{m}^{2}$ ) with a BMI $\geq 25 \mathrm{~kg} / \mathrm{m}^{2}$. There was no significant difference in mean age, height, body weight, and BMI between $\mathrm{CD}$ and UC patients. In CD patients, 7 patients (32\%) had mild to moderate disease (CDAI $<220)$, and 15 patients $(68 \%)$ had moderate to severe disease (CDAI 220-450). The Lichtiger index demonstrated that $9 \mathrm{UC}$ patients $(50 \%)$ had mild/moderate disease (Lichtiger index $<11$ ), and 9 UC patients $(50 \%)$ had severe disease (Lichtiger index $\geq 11$ ). Results from the Seo index identified eight patients (44\%) with moderate disease (Seo index $<220$ ), and 10 patients $(56 \%)$ with severe disease (Seo index $\geq 220$ ). Seventeen patients with $\mathrm{CD}$ and 11 patients with UC received TPN, 5 patients with $C D$ and 7 patients with $U C$ received peripheral parenteral nutrition. Twenty-one patients with $\mathrm{CD}$ switched to EN from PN after treatment. The number of surgical operations performed was significantly more in $\mathrm{CD}$ patients than in UC patients.

Nutritional screening. As shown in Table 2, according to SGA, $41.0 \%$ of CD patients and $33.3 \%$ of UC patients were considered severely malnourished. According to MUST, $68.2 \%$ of CD patients and $61.1 \%$ of UC patients were at high risk for malnutrition. CD patients were frequently qualified as severely malnourished by SGA detection and high-risk by MUST when compared to UC patients, but there were no significant difference between the patients for these parameters $(p=0.545, p=0.767)$. According to NRS2002, 77.3\% of CD patients and $83.3 \%$ of UC patients were considered at risk for malnutrition. Body weight loss over the 6-month period in CD and UC patients was $9.7 \pm 6.8 \%$ and $7.1 \pm 6.5 \%$, respectively, although there was no significant difference between the groups $(p=0.737)$. According to PNI, $90.9 \%$ of CD patients and $83.3 \%$ of UC patients were considered at high risk (PNI $\leq 40)$. The mean PNI in $\mathrm{CD}$ and $\mathrm{UC}$ patients was $34.0 \pm 5.6$ and $32.5 \pm 6.9$, respectively. According to CONUT, $36.4 \%$ of $\mathrm{CD}$ and $44.5 \%$ of UC patients were considered severe,

Table 1. Characteristics of patients with IBD $(n=40)$

\begin{tabular}{|c|c|c|c|}
\hline Characteristics & CD patients $(n=22)$ & UC patients $(n=18)$ & $p$ value \\
\hline Gender (male/female) & $16 / 6$ & $12 / 6$ & \\
\hline Age (years) & $30.8 \pm 9.5$ & $39.4 \pm 16.9$ & 0.064 \\
\hline Height $(\mathrm{cm})$ & $168.5 \pm 7.5$ & $163.5 \pm 8.7$ & 0.062 \\
\hline Body weight $(\mathrm{kg})$ & $53.0 \pm 6.4$ & $51.2 \pm 8.9$ & 0.466 \\
\hline BMI $\left(\mathrm{kg} / \mathrm{m}^{2}\right)$ & $18.7 \pm 2.5$ & $19.1 \pm 2.5$ & 0.643 \\
\hline Type of CD (ileal/ileocolitic/colitic) & $6 / 13 / 3$ & - & \\
\hline Type of UC (total colitis/left-side colitis) & - & $12 / 6$ & \\
\hline \multicolumn{4}{|l|}{ Activity index } \\
\hline CDAl for CD & $255.0 \pm 88.7$ & - & \\
\hline Seo index for UC & - & $222.2 \pm 33.5$ & \\
\hline Lichtiger index for UC & - & $11.3 \pm 2.8$ & \\
\hline \multicolumn{4}{|l|}{ Treatments } \\
\hline $\mathrm{PSL} \geq 20 \mathrm{mg} / \mathrm{day}$ & 5 & 16 & \\
\hline$<20 \mathrm{mg} /$ day & 17 & 2 & \\
\hline Azathioprine or Cyclosporine & 10 & 12 & \\
\hline Leukocytapheresis & 0 & 10 & \\
\hline Anti-TNF- $\alpha$ & 18 & 2 & \\
\hline \multicolumn{4}{|l|}{ Nutritional therapy } \\
\hline TPN/PPN & $17 / 5$ & $11 / 7$ & 0.267 \\
\hline EN (switched from PN) & 21 & - & \\
\hline Surgical operation & 9 & 1 & 0.010 \\
\hline Duration of the disease (years) & $4.6 \pm 6.0$ & $3.6 \pm 6.1$ & 0.642 \\
\hline
\end{tabular}

IBD, inflammatory bowel disease; CD, Crohn's disease; UC, ulcerative colitis; BMI, body mass index; CDAl, Crohn's Disease Activity Index; PSL, prednisolone; anti-TNF- $\alpha$, anti-tumor necrosis factor- $\alpha$; TPN, total parenteral nutrition; PPN, peripheral parenteral nutrition; EN, enteral nutrition; PN, parenteral nutrition. Each value represents the mean \pm SD. 
Table 2. Nutritional screening

\begin{tabular}{|c|c|c|c|}
\hline & CD patients (\%) & UC patients (\%) & $p$ value \\
\hline \multicolumn{4}{|l|}{ SGA } \\
\hline Well nourished & 4.5 & 0 & 0.545 \\
\hline Moderately malnourished & 54.5 & 66.7 & \\
\hline Severely malnourished & 41.0 & 33.3 & \\
\hline \multicolumn{4}{|l|}{ MUST } \\
\hline Low risk & 13.6 & 11.1 & 0.767 \\
\hline Medium risk & 18.2 & 27.8 & \\
\hline High risk & 68.2 & 61.1 & \\
\hline \multicolumn{4}{|l|}{ NRS2002 } \\
\hline Without nutritional risk & 22.7 & 16.7 & 0.634 \\
\hline With nutritional risk & 77.3 & 83.3 & \\
\hline \multicolumn{4}{|l|}{ PNI } \\
\hline Low risk & 9.1 & 16.7 & 0.471 \\
\hline High risk & 90.9 & 83.3 & \\
\hline \multicolumn{4}{|l|}{ CONUT } \\
\hline Normal & 4.5 & 11.1 & 0.766 \\
\hline Light & 13.6 & 11.1 & \\
\hline Moderate & 45.5 & 33.3 & \\
\hline Severe & 36.4 & 44.5 & \\
\hline
\end{tabular}

SGA, subjective global assessment; MUST, malnutrition universal screening tool; NRS2002, nutritional risk screening 2002; PNI, prognostic nutritional index; CONUT, controlling nutritional status.

Table 3. Laboratory tests and inflammatory cytokines

\begin{tabular}{lccc}
\hline & CD patients & UC patients & $p$ value \\
\hline Laboratory tests & & & \\
TP $(\mathrm{g} / \mathrm{dl})$ & $6.4 \pm 0.8$ & $5.8 \pm 0.6$ & 0.009 \\
Alb $(\mathrm{g} / \mathrm{dl})$ & $2.8 \pm 0.5$ & $2.6 \pm 0.6$ & 0.234 \\
T-cho $(\mathrm{mg} / \mathrm{dl})$ & $127.5 \pm 31.8$ & $125.9 \pm 36.5$ & 0.882 \\
TG $(\mathrm{mg} / \mathrm{dl})$ & $82.9 \pm 31.1$ & $90.0 \pm 57.5$ & 0.292 \\
Hb (g/dl) & $11.0 \pm 2.0$ & $10.3 \pm 3.0$ & 0.430 \\
CRP $(\mathrm{mg} / \mathrm{dl})$ & $6.6 \pm 6.8$ & $6.1 \pm 5.5$ & 0.925 \\
Inflammatory cytokines & & & \\
IL-6 (pg/ml) & $13.8 \pm 13.4$ & $17.0 \pm 14.0$ & 0.506 \\
TNF- $\alpha(\mathrm{pg} / \mathrm{ml})$ & $2.0 \pm 0.7$ & $2.7 \pm 1.7$ & 0.108 \\
\hline
\end{tabular}

$\mathrm{TP}$, total protein; Alb, albumin; T-cho, total cholesterol; TG, triglyceride; Hb, hemoglobin; CRP, C-reactive protein; IL-6, interleukin-6; TNF- $\alpha$, tumor necrosis factor- $\alpha$. Each value represents the mean \pm SD.

Table 4. Energy metabolism

\begin{tabular}{lccc}
\hline & CD patients & UC patients & $p$ value \\
\hline mREE (kcal/day) & $1,388.7 \pm 226.6$ & $1,341.6 \pm 252.6$ & 0.538 \\
pREE (kcal/day) & $1,413.1 \pm 127.9$ & $1,324.6 \pm 174.8$ & 0.072 \\
$\mathrm{mREE} /$ body weight (kcal/kg/day) & $26.3 \pm 3.8$ & $26.3 \pm 3.0$ & 0.986 \\
pREE/body weight (kcal/kg/day) & $26.8 \pm 2.1$ & $26.1 \pm 2.8$ & 0.378 \\
$\mathrm{mREE} / \mathrm{pREE}$ & $0.98 \pm 0.13$ & $1.01 \pm 0.13$ & 0.475 \\
RQ & $0.81 \pm 0.07$ & $0.79 \pm 0.09$ & 0.377 \\
\hline
\end{tabular}

mREE, measured resting energy expenditure; $\mathrm{pREE}$, predicted resting energy expenditure; RQ, respiratory quotient. Each value represents the mean \pm SD.

and the mean CONUT in CD and UC patients was $7.50 \pm 2.9$ and $8.0 \pm 3.3$, respectively. There was no significant difference in PNI and CONUT between CD and UC patients.

Laboratory tests and inflammatory cytokines. Total protein in UC patients $(5.8 \pm 0.6 \mathrm{~g} / \mathrm{dl})$ was significantly decreased compared to that in $\mathrm{CD}$ patients $(6.4 \pm 0.8 \mathrm{~g} / \mathrm{dl})$. There were $54.5 \%$ and $83.3 \%$ of $\mathrm{CD}$ and UC patients with serum albumin levels $<3.0 \mathrm{~g} / \mathrm{dl}(p=0.053)$, and $72.7 \%$ and $66.7 \%$ with total cholesterol levels $<140 \mathrm{mg} / \mathrm{dl}(p=0.677)$, respectively. The results also indicated that $73.7 \%$ and $66.7 \%$ of $\mathrm{CD}$ and $\mathrm{UC}$ patients, respectively, had plasma IL-6 levels $>4 \mathrm{pg} / \mathrm{ml}$. Further- more, $11.1 \%$ and $37.5 \%$ of CD and UC patients had serum TNF- $\alpha$ levels $>2.8 \mathrm{pg} / \mathrm{ml}$, respectively. There were no significant differences in the laboratory tests and inflammatory cytokines for CD and UC patients except for serum total protein (Table 3 ).

Energy metabolism and its relationship to disease activity.

In $C D$ patients, mREE determined by indirect calorimetry was $1388.7 \pm 226.6 \mathrm{kcal} /$ day and pREE calculated by the HarrisBenedict equation was $1413.1 \pm 127.9 \mathrm{kcal} /$ day. In UC patients, mREE was $1341.6 \pm 252.6 \mathrm{kcal} /$ day and $\mathrm{pREE}$ was $1324.6 \pm$ $174.8 \mathrm{kcal} /$ day. There were no significant differences in mREE/ body weight and RQ between CD and UC patients (Table 4). 


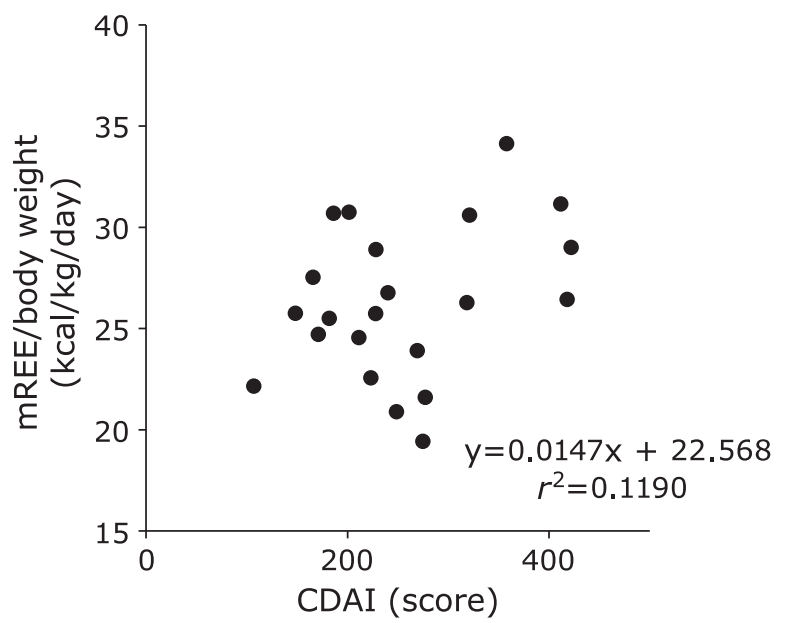

Fig. 1. Correlation between measured resting energy expenditure/body weight (mREE/body weight) and Crohn's Disease Activity Index (CDAI) in $\mathrm{CD}$ patients. There was no correlation between mREE/body weight and CDAl in CD patients.

In $\mathrm{CD}$ patients, there was no significant correlation between $\mathrm{mREE} /$ body weight and disease activity index (Fig. 1). However, there was a positive correlation between $\mathrm{mREE} /$ body weight and activity index in UC patients (Fig. 2). In both CD and UC patients, there was no significant correlation between CRP levels and $\mathrm{mREE} /$ body weight or CRP levels and mREE/pREE. Results in Fig. 3 indicate a positive correlation between IL-6 levels and $\mathrm{mREE} / \mathrm{pREE}$ or $\mathrm{mREE} /$ body weight in CD patients. Furthermore, in UC patients, there was a positive tendency of correlation between IL-6 levels and mREE/pREE ( $p=0.062$ ) (Fig. 4). However, there was no significant correlation between TNF- $\alpha$ levels and $\mathrm{mREE} / \mathrm{pREE}$ or $\mathrm{mREE} /$ body weight in $\mathrm{CD}$ and UC patients.

\section{Discussion}

It is well known that malnutrition is a significant health problem in IBD patients. It is also accepted that the prevalence of nutritional deficiencies and malnutrition is higher in patients with CD than in patients with UC. It has been hypothesized that increased malnutrition in CD patients is associated with transmural inflammation of the gastrointestinal tract while UC is characterized by inflammation limited to the colonic mucosa. However, despite the indisputable role of IBD in malnutrition, there are few reports on the comparative analysis of nutritional status and energy metabolism of CD and UC patients. One report by Han et al..$^{(9)}$ demonstrated a high prevalence of abnormal laboratory tests including serum albumin and micronutrient levels in CD patients. In our study, we investigated laboratory tests and nutritional status by using SGA, MUST, NRS2002, PNI, and CONUT. Here, we clearly demonstrated that the nutritional condition of hospitalized $\mathrm{UC}$ patients is poor and almost equal to that of $\mathrm{CD}$ patients.

Mijac et al. ${ }^{(35)}$ reported no significant difference in nutritional parameters between CD and UC patients except for lower midarm muscle circumference in UC patients. However, patients enrolled in their study were well nourished compared to patients enrolled in our study, and had BMI and serum albumin levels $21.4 \pm 3.7 \mathrm{~kg} / \mathrm{m}^{2}$ and $3.1 \pm 0.7 \mathrm{~g} / \mathrm{dl}$, respectively. Conversely, in our study, the mean BMI was $18.9 \pm 2.5 \mathrm{~kg} / \mathrm{m}^{2}$, and serum albumin levels were $2.7 \pm 0.5 \mathrm{~g} / \mathrm{dl}$. Furthermore, Mijac et al. and colleagues conducted their study in Serbia where the prevalence of men and women over 20 years old who are overweight or obese was higher than $50 \%{ }^{(36)}$ In Japan, the prevalence of men and women over 20 years old who are overweight or obese is $28.9 \%$ and $17.6 \%$, respectively. Additionally, our study enrolled IBD patients with severe disease and a compromised nutritional status, and the apparent difference in race should be taken into account when comparing the studies. In this study, we identified no significant difference in the nutritional status of $\mathrm{CD}$ and $\mathrm{UC}$ patients, which is supported by results published by Mijac et al. ${ }^{(35)}$ However, both groups demonstrated risk for malnourishment, highlighting the necessity of nutritional management in both patients with active $C D$ and $U C$, although the number of patients in this study was not large as Mijac's study.

This is the first report to compare resting energy expenditure in $\mathrm{CD}$ and UC patients although several reports have documented that IBD patients exhibit energy metabolism shifts to a hypermetabolic status. ${ }^{(10-14,16,17)}$ Previously, we reported that Japanese IBD patients had significantly higher mREE when compared to healthy controls by using indirect calorimetry. ${ }^{(18,19)}$ In this study, there was no significant difference in mREE or RQ between CD and UC patients. However, a positive correlation between $\mathrm{mREE}$
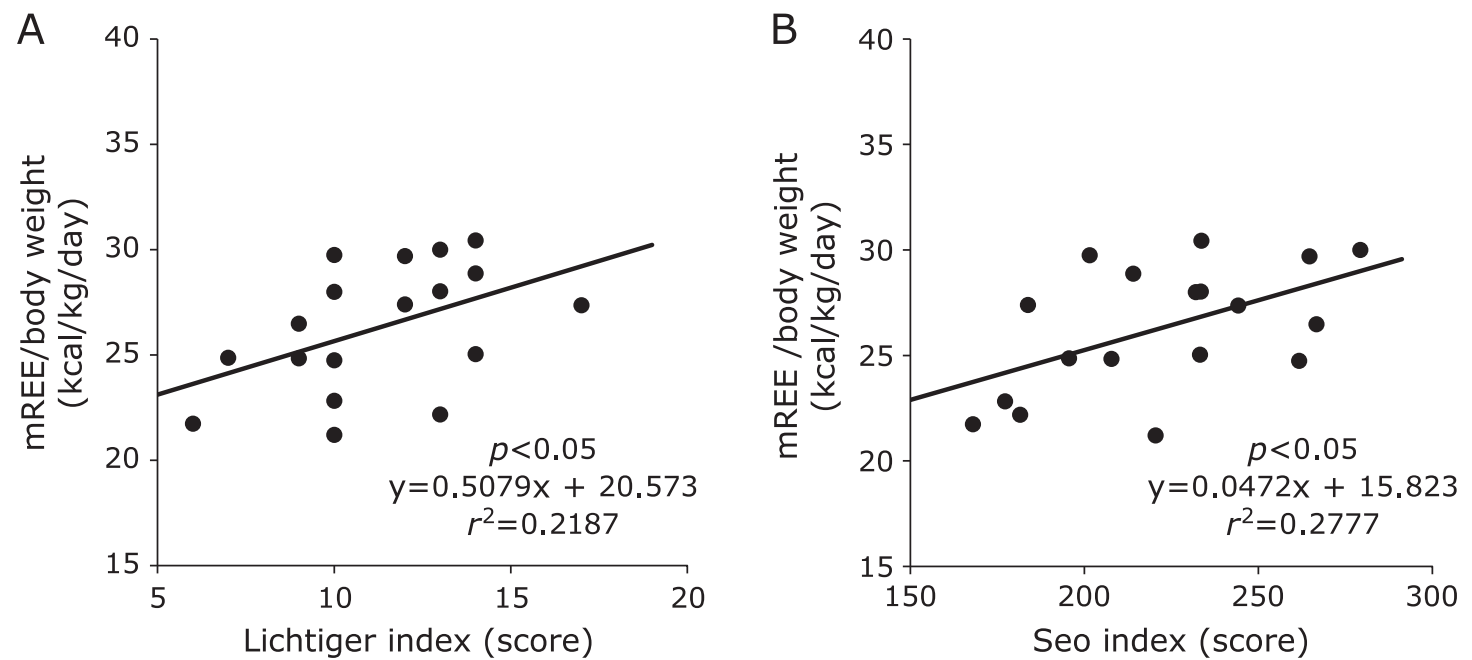

Fig. 2. Correlation between measured resting energy expenditure/body weight (mREE/body weight) and the Lichtiger and Seo indices in UC patients. The mREE/body weight in UC patients exhibited positive correlation with both the Lichtiger index (A) and Seo index (B). 

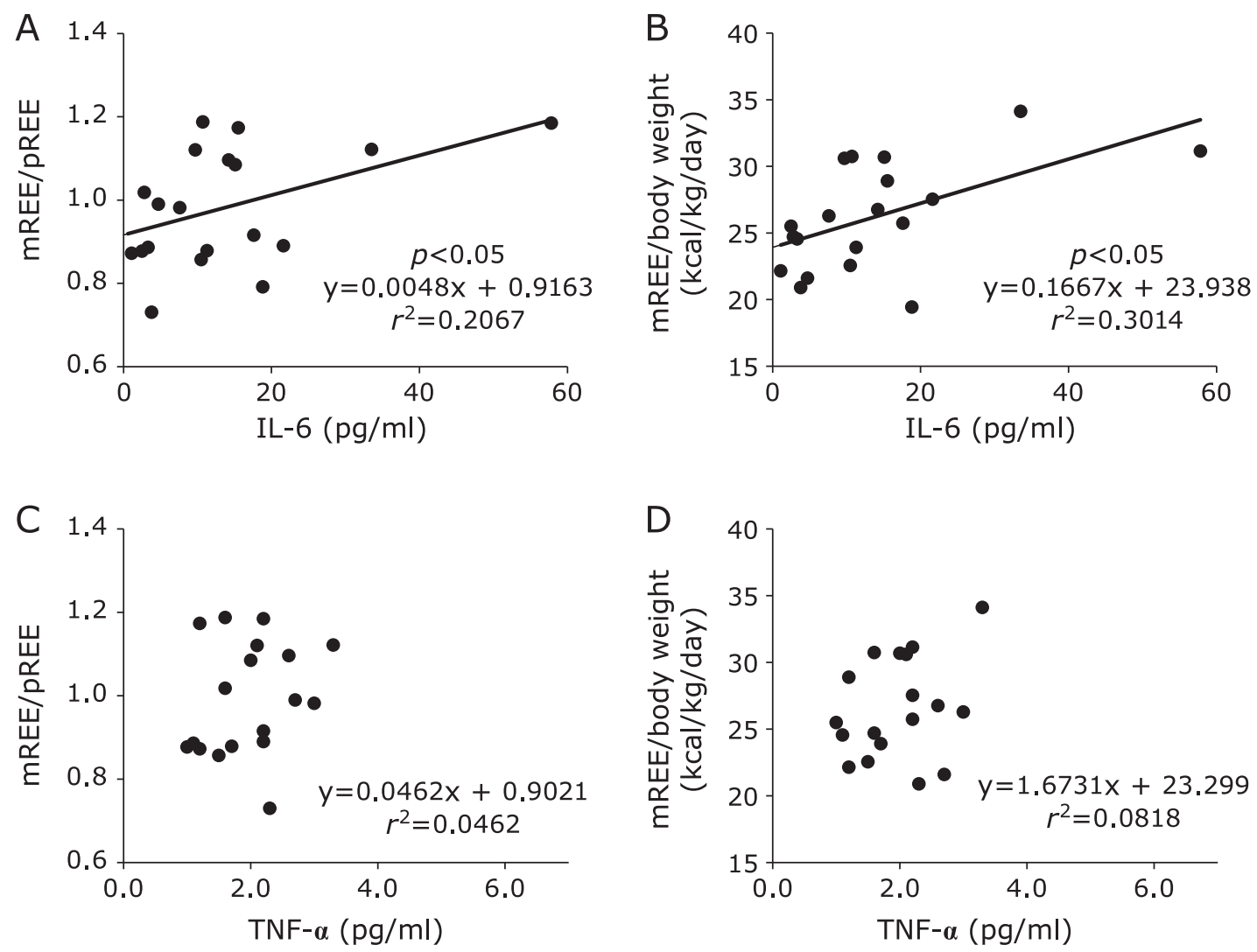

Fig. 3. Correlation between interleukin-6 (IL-6) levels and tumor necrosis factor- $\alpha$ (TNF- $\alpha$ ) levels and measured resting energy expenditure/predicted resting energy expenditure (mREE/pREE) or mREE/body weight in CD patients. IL-6 levels in CD patients exhibited positive correlation with mREE/pREE (A) and $\mathrm{mREE} /$ body weight (B). However, there was no significant correlation between TNF- $\alpha$ and mREE/pREE (C) or mREE/body weight (D) in CD patients.

and disease activity was identified in UC patients.

Several studies have investigated the relationship between energy metabolism and disease activity in CD patients. For example, Wiskin et al. ${ }^{(37)}$ reported that there was no relationship between disease activity and mREE or CRP in childhood CD patients. Recently, Gong et al. ${ }^{(38)}$ also reported no significant correlation between mREE and disease activity when using CDAI in adult CD patients. In our study, we showed there was no relationship between energy metabolism and CDAI or CRP in CD patients, which is supported by observations from previous studies. However, in UC patients, the relationship between energy metabolism and disease activity had not been thoroughly investigated. Previously, we reported a positive correlation between mREE and the Lichtiger index in UC patients. ${ }^{(19)}$ Here, we clearly demonstrated that energy metabolism correlated with the Lichtiger and Seo indices, and we confirmed that disease activity affected the energy metabolism in UC patients. These results suggest that nutritional status of UC patients is determined by energy requirements according to disease activity.

It has been shown that disease activity and CRP levels are not always linked in active IBD patients. ${ }^{(39,40)}$ Our results presented here indicate no significant correlation between $\mathrm{mREE}$ and CRP levels in $\mathrm{CD}$ and $\mathrm{UC}$ patients. This confirms previous study by Wiskin et al. ${ }^{(41)}$ who identified no significant correlation between $\mathrm{mREE}$ and CRP levels in children with IBD.

The results in this study showed that energy expenditure was correlated with IL-6 levels, but not with TNF- $\alpha$ levels. Proinflammatory cytokines significantly affect energy metabolism in patients with systemic inflammatory diseases including IBD. ${ }^{(42,43)}$
Previously, we reported that IL-6 levels correlated with energy metabolism in CD patients. ${ }^{(34)}$ In this study, IL-6 levels correlated with $\mathrm{mREE} / \mathrm{pREE}$ in CD patients $(p<0.05)$ and UC patients $(p=0.062)$. In CD patients, serum IL-6 level but not serum TNF$\alpha$ level was reported to be important marker as disease activity. ${ }^{(44)}$ Furthermore, it was reported that the increased production of proinflammatory cytokines, particularly of IL-6 and IL-8, play an important role in the pathogenesis of UC. ${ }^{(45)}$ In this study, we demonstrate that energy metabolism correlated to IL-6 levels in $\mathrm{CD}$ and UC patients. Kotani et al. ${ }^{(46)}$ reported that $\mathrm{mREE} / \mathrm{pREE}$ was significantly correlated to IL-6 levels and was not correlated with TNF- $\alpha$ levels after surgical trauma.

In conclusion, hospitalized $\mathrm{CD}$ and UC patients exhibited severe nutritional status and had similar energy expenditure. However, energy expenditure significantly correlated with disease activity in UC patients, but not in CD patients. Therefore, it is important to determine the daily energy requirements correlated with disease activity for active UC patients in order to improve nutritional conditions for these patients.

\section{Conflict of Interest}

No potential interests of conflict were disclosed. 

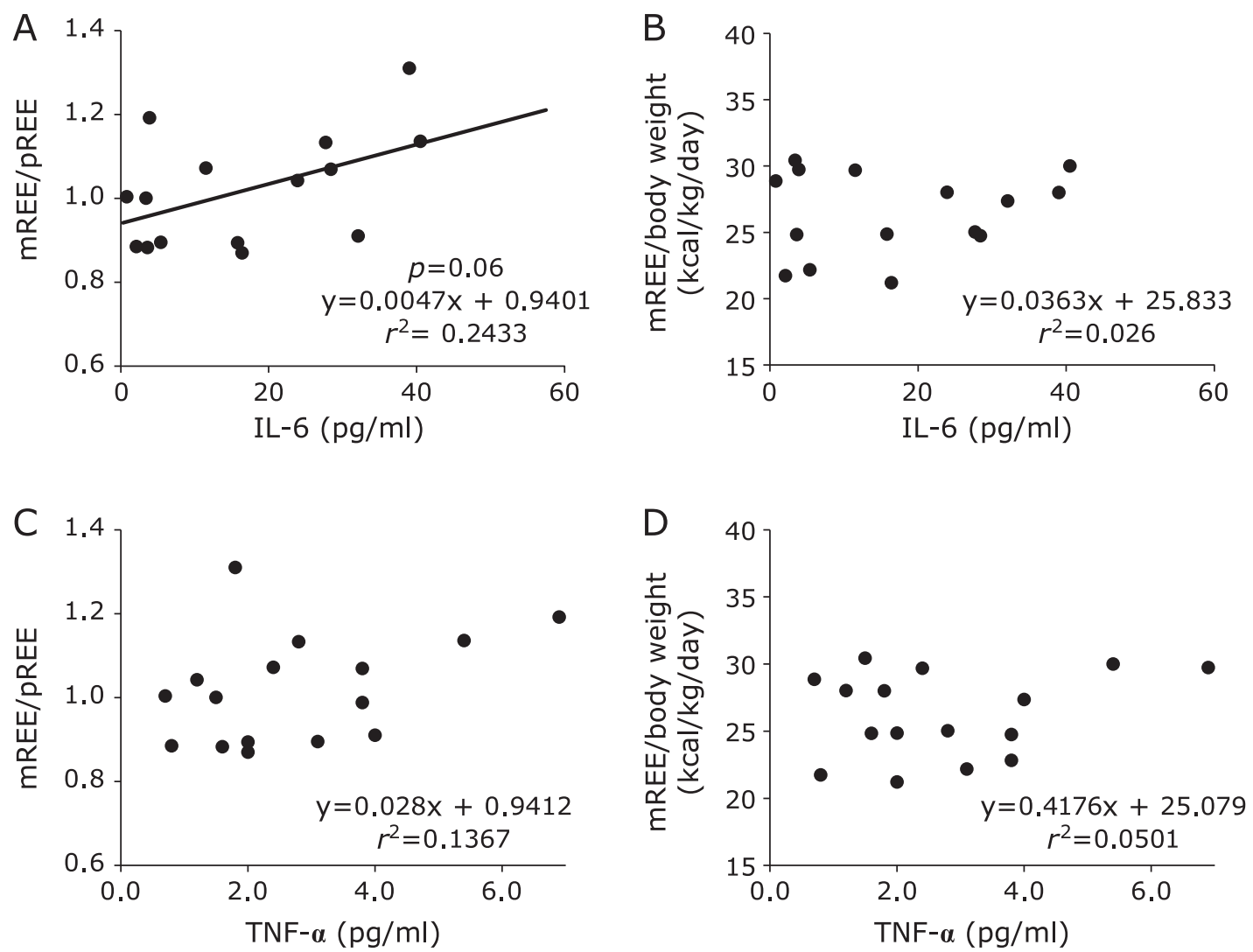

Fig. 4. Correlation between interleukin-6 (IL-6) and tumor necrosis factor- $\alpha$ (TNF- $\alpha$ ) levels and measured resting energy expenditure/predicted resting energy expenditure (mREE/pREE) or mREE/body weight in UC patients. IL-6 levels in UC patients exhibited positibe correlation with mREE/ pREE $(p=0.062)(A)$. However, there was no significant correlation between IL- 6 and $\mathrm{mREE} /$ body weight $(\mathrm{B})$, or correlation between TNF- $\alpha$ and $\mathrm{mREE} / \mathrm{pREE}(\mathrm{C})$ or $\mathrm{mREE} /$ body weight (D) in UC patients.

\section{References}

1 Mayer L. Evolving paradigms in the pathogenesis of IBD. $J$ Gastroenterol 2010; 45: 9-16

2 Andoh A, Kuzuoka H, Tsujikawa T, et al. Multicenter analysis of fecal microbiota profiles in Japanese patients with Crohn's disease. J Gastroenterol 2012; 47: 1298-1307.

3 Andoh A, Imaeda H, Aomatsu T, et al. Comparison of the fecal microbiota profiles between ulcerative colitis and Crohn's disease using terminal restriction fragment length polymorphism analysis. J Gastroenterol 2011; 46: 479486.

4 Farmer RG, Hawk WA, Turnbull RB Jr. Clinical patterns in Crohn's disease: a statistical study of 615 cases. Gastroenterology 1975; 68: 627-635.

5 Mekhjian HS, Switz DM, Melnyk CS, Rankin GB, Brooks RK. Clinical features and natural history of Crohn's disease. Gastroenterology 1979; 77: 898-906.

6 Afonso JJ, Rombeau JL. Nutritional care for patients with Crohn's disease. Hepatogastroenterology 1990; 37: 32-41.

7 Driscoll RH Jr, Resenberg IH. Total parenteral nutrition in inflammatory bowel disease. Med Clin North Am 1978; 62: 185-201.

8 Massironi S, Rossi RE, Cavalcoli FA, Della Valle S, Fraguelli M, Conte D. Nutritional deficiencies in inflammatory bowel disease: therapeutic approaches. Clin Nutr 2013; 32: 904-910.

9 Han PD, Burke A, Baldassano RN, Rombeau JL. Nutrition and inflammatory bowel disease. Gastroentrol Clin North Am 1999; 28: 423-443.

10 Chan AT, Fleming CR, O'Fallon WM, Huizenga KA. Estimated versus measured basal energy requirement in patients with Crohn's disease. Gastroenterology 1986; 91: 75-78.

11 Kushner RF, Schoeller DA. Resting and total energy expenditure in patients with inflammatory bowel disease. Am J Clin Nutr 1991; 53: 161-165.

12 Stokes MA, Hill GL. Total energy expenditure in patients with Crohn's disease: measured by the combined body scan technique. JPEN J Parenter
Enteral Nutr 1993; 17: 3-7.

13 Rigaud D, Cerf M, Angel Alberto L, Sobhani I, Carduner MJ, Mignon M. Increase of resting energy expenditure during flare-ups in Crohn's disease. Gastroenterol Clin Biol 1993; 17: 932-937 (in French).

14 Al-Jaouni R, Hébuterne X, Pouget I, Rampal P. Energy metabolism and substrate oxidation in patients with Crohn's disease. Nutrition 2000; 16: 173178.

15 Schneeweiss B, Lochs H, Zauner C, et al. Energy and substrate metabolism in patients with active Crohn's disease. J Nutr 1999; 129: 844-848.

16 Barot LR, Rombeau JL, Steinberg JJ, Crosby LO, Feurer ID, Mullen JL. Energy expenditure in patients with inflammatory bowel disease. Ann Surg 1981; 116: 460-462.

17 Capristo E, De Gaetano A, Mingrone G, et al. Multivariate identification of metabolic features in inflammatory bowel disease. Metabolism 1999; 48: 952-956.

18 Sasaki M, Johtatsu T, Kurihara M, et al. Energy metabolism in Japanese patients with Crohn's disease. J Clin Biochem Nutr 2010; 46: 68-72.

19 Sasaki M, Johtatsu T, Kurihara M, et al. Energy expenditure in Japanese patients with severe or moderate ulcerative colitis. J Clin Biochem Nutr 2010; 47: $32-36$.

20 Ueno F, Matsui T, Matsumoto T, et al. Evidence-based clinical practice guidelines for Crohn's disease, integrated with formal consensus of experts in Japan. J Gastroenterol 2013; 48: 31-72.

21 Hibi T, Ueno F, Matsuoka K, Lee TC; Research Group for Intractable Inflammatory Bowel Disease 2006. Guidelines for management of ulcerative colitis in Japan-Developed through integration of evidence and consensus among experts-. IBD Research 2010; 4: 189-239.

22 Baker JP, Detsky AS, Wesson DE, et al. Nutritional assessment: a comparison of clinical judgement and objective measurements. N Engl J Med 1982; 306: 969-972. 
23 Detsky AS, Baker JP, Mendelson RA, Wolman SL, Wesson DE, Jeejeebhoy $\mathrm{KN}$. Evaluating the accuracy of nutritional assessment techniques applied to hospitalized patients: methodology and comparisons. JPEN J Parenter Enteral Nutr 1984; 8: 153-159.

24 Stratton RJ, Hackston A, Longmore D, et al. Malnutrition in hospital outpatients and inpatients: prevalence, concurrent validity and ease of use of the 'malnutrition universal screening tool' 'MUST' for adults. Br J Nutr 2004; 92: 799-808.

25 Kondrup J, Allison SP, Elia M, et al. ESPEN guidelines for nutrition screening 2002. Clin Nutr 2003; 22: 415-421.

26 Onodera T, Goseki N, Kosaki G. Prognostic nutritional index in gastrointestinal surgery of malnourished cancer patients. Nihon Geka Gakkai Zasshi 1984; 85: 1001-1005 (in Japanese).

27 Ignacio de Ulíbarri J, González-Madroño A, de Villar NG, et al. CONUT: a tool for controlling nutritional status. First validation in a hospital population. Nutr Hosp 2005; 20: 38-45.

28 Best WR, Becktel JM, Singleton JW, Kern F Jr. Development of a Crohn's disease activity index. National Cooperative Crohn's Disease Study. Gastroenterology 1976; 70: 439-444.

29 Best WR, Becktel JM, Singleton JW. Rederived values of the eight coefficients of the Crohn's Disease Activity Index (CDAI). Gastroenterology 1979; 77: 843-846.

30 Lichtiger S, Present DH, Kornbluth A, et al. Cyclosporine in severe ulcerative colitis refractory to steroid therapy. $N$ Engl J Med 1994; 330: $1841-1845$

31 Seo M, Okada M, Yao T, Ueki M, Arima S, Okumura M. An index of disease activity in patients with ulcerative colitis. Am J Gastroenterol 1992; 87: 971976.

32 Sasaki M, Okamoto H, Johtatsu T, et al. Resting energy expenditure in patients undergoing pylorus preserving pancreatoduodenectomies for bile duct cancer or pancreatic tumors. J Clin Bilchem Nutr 2011; 48: 183-186.

33 Okamoto H, Sasaki M, Johtatsu T, et al. Resting energy expenditure and nutritional status in patients undergoing transthoracic esophagectomy for esophageal cancer. J Clin Biochem Nutr 2011; 49: 169-173.

34 Nishida N, Sasaki M, Kurihara M, et al. Changes of energy metabolism, nutritional status and serum cytokine levels in patients with Crohn's disease after anti-tumor necrosis factor- $\alpha$ therapy. J Clin Biochem Nutr 2013; 53: $122-127$.

35 Mijac DD, Janković GL, Jorga J, Krstić MN. Nutritional status in patients with active inflammatory bowel disease: prevalence of malnutrition and methods for routine nutritional assessment. Eur J Intern Med 2010; 21: 315 319.

$36 \mathrm{Ng} \mathrm{M}$, Fleming $\mathrm{T}$, Robinson $\mathrm{M}$, et al. Global, regional, and national prevalence of overweight and obesity in children and adults during 1980-2013: a systematic analysis for the Global Burden of Disease Study 2013. Lancet 2014; 384: 766-781.

37 Wiskin AE, Wootton SA, Cornelius VR, Afzal NA, Elia M, Beattie RM. No relation between disease activity measured by multiple methods and REE in childhood Crohn disease. J Pediatr Gastroenterol Nutr 2012; 54: 271-276.

38 Gong J, Zuo L, Guo Z, et al. Impact of disease activity on resting energy expenditure and body composition in adult Crohn's disease: a prospective longitudinal assessment. JPEN J Parenter Enteral Nutr 2014. [Epub ahead of print]

39 Schoepfer AM, Beglinger C, Straumann A, Trummler M, Renzulli P, Seibold F. Ulcerative colitis: correlation of the Rachmilewitz endoscopic activity index with fecal calprotectin, clinical activity, C-reactive protein, and blood leukocytes. Inflamm Bowel Dis 2009; 15: 1851-1858.

40 Moscandrew ME, Loftus EV Jr. Diagnostic advances in inflammatory bowel disease (imaging and laboratory). Curr Gastroenterol Rep 2009; 11: 488-495.

41 Wiskin AE, Wootton SA, Culliford DJ, Afzal NA, Jackson AA, Beattie RM. Impact of disease activity on resting energy expenditure in children with inflammatory bowel disease. Clin Nutr 2009; 28: 652-656.

42 Bonville DA, Parker TS, Levine DM, et al. The relationships of hypocholesterolemia to cytokine concentrations and mortality in critically ill patients with systemic inflammatory response syndrome. Surg Infect (Larchmt) 2004; 5: 39-49.

43 Chen X, Xun K, Chen L, Wang Y. TNF-alpha, a potent lipid metabolism regulator. Cell Biochem Funct 2009; 27: 407-416.

44 Louis E, Belaiche J, van Kemseke C, et al. A high serum concentration of interleukin-6 is predictive of relapse in quiescent Crohn's disease. Eur J Gastroenterol Hepatol 1997; 9: 939-944.

45 Murata Y, Ishiguro Y, Itoh J, Munakata A, Yoshida Y. The role of proinflammatory and immunoregulatory cytokines in the pathogenesis of ulcerative colitis. J Gastroenterol 1995; 30: 56-60.

46 Kotani G, Usami M, Kasahara H, Saitoh Y. The relationship of IL-6 to hormonal mediators, fuel utilization, and systemic hypermetabolism after surgical trauma. Kobe J Med Sci 1996; 42: 187-205. 